\title{
Penetrating Wounds of the Abdomen: Treatment in Times of Conflict at the Bangassou Regional University Hospital in the Central African Republic
}

\section{Doui Doumgba Antoine ${ }^{1 *}$, Moute Jerry Martial $^{2}$, Ngboko Mirotiga Pétula Anicette ${ }^{3}$ and Piamale Germain ${ }^{4}$}

${ }^{1}$ Doctor, Surgeon, Associate Lecturer, Head of General and Visceral Surgery, CHU of Sino-Central African Friendship, Bangui, Central African Republic

${ }^{2}$ Doctor, General Practitioner, Department of Surgery and Surgical Specialties, Faculty of Health Sciences, University of Bangui, Central African Republic

${ }^{3}$ Doctor, Resident Physician in General Surgery, CHU of Sino-Central African Friendship, Bangui, Central African Republic

${ }^{4}$ Doctor, PhD Student in Public Health, Doctoral School of Human and Veterinary

Health Sciences University of Bangui, Bangui, Central African Republic

*Corresponding Author: Doui Doumgba Antoine, Doctor, Surgeon, Associate Lecturer, Head of General and Visceral Surgery, CHU of Sino-Central African Friendship, Bangui, Central African Republic.
Received: October 27, 2021

Published: December 13, 2021

(C) All rights are reserved by Doui Doumgba Antoine., et al.

\section{Abstract}

Introduction: Wounds of the abdomen are traumas with rupture of the continuity of the abdominal wall. The circumstances of their occurring are varied but are often related to the increase in crime in civilian practice or during armed conflicts. Objective: to study the epidemiological, diagnostic and therapeutic aspects of penetrating wounds of the abdomen at the level of the general surgery department of the Bangassou Regional University Hospital in the south-east of the Central African Republic. Patients and methods: This is a descriptive retrospective study of cases of penetrating wounds of the abdomen recorded and treated during the period from May 12, 2017 to May 12, 2019 at the said CHU. Results: The series consisted of 84 patients and male subjects accounted for $88.1 \%$. The sex ratio $(\mathrm{M} / \mathrm{F})$ was 7.4. The average age of patients was 30.4 years $( \pm 12.7$ years). Patients aged $14-23$ years were more affected (39.29\%). Nearly 2/3 of the victims were under 45 years of age. Many of the victims came from the area of the locality of Bangassou (44\%) and Gambo (21\%) which constituted the epicenter of armed conflict in the region. The injured were willingly unemployed (45.2\%) followed by farmers (27.4\%). The circumstances of the wounds were clashes during armed conflicts (51.2\%) and criminal assaults (42.8\%). The wounded had arrived under the guidance of a non-governmental organization (40.5 per cent) or their relatives (33.33 per cent). The average time to admission was 1.2 days. The firearm was the most incriminated vulnerable agent in $76.2 \%$ of cases. Wounds were mainly in the right hypochondrium (35.7\%), the left iliac fright (17.9\%) and the hypogastrium (17.9\%). In 81\% of cases these wounds were ponctiform. The diagnosis of penetration was based on signs of hemoperitoneum (57.1\%) and peritonitis (27.4\%). Abdominal wounds were associated with extra abdominal lesions in $17.8 \%$ of cases consisting of open fractures of limbs, bursa lesions and chest wounds. All the injured were operated on after brief medical resuscitation. A safe iso rhesus whole blood transfusion was useful in 55 injured (65.5\%), including 30 in pre-operative and 15 intraoperatively. General anesthesia was used in all patients with orotracheal intubation. The first route was the median laparotomy above and sub umbilical. The lesions concerned the liver (37.1\%), hail (29.8\%), and colon (12.7\%). In 5.8\% of cases no lesions were found. The main surgical procedures performed were excision-suture of organs (50 cases) and resection-anastomosis (10 cases). Morbidity is dominated by infection of the surgical 
site in $1.2 \%$ of cases. The average length of hospital stay was 09 days (extremes 5 and 25 days). We deplore 8 cases of death or $9.5 \%$, deaths occurred in a hypovolemic shock table.

Conclusion: Abdominal wounds are common in times of armed conflict. They affect young subjects, mostly men. Organic lesions are often multiple. In our context, laparotomy has identified and treated several solid and hollow organ lesions that could compromise the life prognosis of the injured. Our attitude was guided by the remoteness, the context and then the lack of human and material resources that did not allow us to opt for armed surveillance.

Keywords: Surgery; Abdominal Trauma; Penetrating Wound; Laparotomy; Central African Republic

\section{Introduction}

Penetrating wounds of the abdomen (PWA) are traumas with rupture of the continuity of the abdominal wall and peritoneal break-in. When they result in damage to the underlying viscera, the wound is called perforating [1-3]. PWA are becoming more common due to increased crime, the proliferation of fire arms and the persistence of conflicts [4]. in developed countries, the management of penetrating wounds of the abdomen is more or less well codified in countries with limited means. However, after the observation of a significant number of useless or white laparotomy, attitudes are still subject to controversy. The debate lies between systematic exploratory laparotomy and an attitude known as "selective abstentions" or armed expectation [2,3,5,6]. In Central African Republic, politico-military conflicts have followed one another in recent years with an increase in the number of wounded, including those in the abdomen [7]. The severity of these types of injuries is increased in precarious situations where diagnostic and therapeutic means are lacking or are not always available at the right time [8]. These findings led us to carry out this study which aims to describe the diagnostic and therapeutic procedures used at this decentralized CHU with almost no senior surgeon.

\section{Patients and Methods}

The study was carried out at the Bangassou Regional and University Hospital Centre. Located in the south-east of the Central African Republic and $734 \mathrm{~km}$ from Bangui, the capital, Bangassou is the capital of the Prefecture of Mbomou. This is a retrospective study of patients with a penetrating wound of the abdomen treated and followed at the level of the general surgery department of the CHU. The study covers the period from 12 May 2017 to 12 May 2019. The records of patients with abdominal trauma regardless of the cause that led to a solution of continuity of the wall with peri- toneal break-in, evisceration, peritoneal fluid, or visceral involvement are retained for our analysis. Non-penetrating abdominal wounds and abdominal bruises were not considered in the study. The data collected came from hospitalization records, patient records, and surgical record records. A pre-established study sheet was used to collect the data and included epidemiological variables (Sex, age, provenance, occupational activities, marital status, route of care), clinical variables (time to care, circumstances and location of trauma, history and lifestyle, nature of the weapon of aggression, clinical signs of penetration, associated extra-abdominal lesions) and treatment-related variables (medical treatment, Surgical treatment, evolution) The data collected was analyzed using Epi-info software. The Chi 2 test was used to compare proportions with a significance threshold of $5 \%$.

\section{Results}

Epidemiological aspects

In two years 1020 patients operated for all causes including 84 injured with a penetrating wound of the abdomen or a frequency of $8.2 \%$. Of the injured, $88.1 \%$ were male and $11.9 \%$ female. The average age of patients was 30.4 years (extremes: 14 years and 63 years.) Subjects aged 14-23 were more numerous (39.4\%), followed by those aged 24-33 (25\%), 34-43 (17.8\%), 44-53 (11.9\%). Subjects over the age of 53 were less numerous (5.9\%).

The wounded come from the different sub-prefectures of the region namely Bangassou (44\%), Gambo (21\%), Ouango (8\%), Bakouma (3\%) and Rafaï (3\%). The injured in other nearby localities accounted for $12 \%$. The wounded reached the hospital with the support of a non-governmental organization (40.5\%), accompanied by family members (33.3\%), after referral by a health worker (26.2\%). According to the occupation of the injured, $45.3 \%$ were unemployed, $27.4 \%$ of farmers, $14.2 \%$ of housewives, $11.9 \%$ of pu- 
Penetrating Wounds of the Abdomen: Treatment in Times of Conflict at the Bangassou Regional University Hospital in the Central African Republic

pils and students and $1.2 \%$ of civil servants. The trauma occurred during armed combat $(33.3 \%)$ or at home when it comes to a criminal assault (25\%). In other cases, trauma occurs as a result of a traffic accident (6\%).

\section{Diagnostic procedures}

The time elapsed between the trauma was on average 1.2 days (extremes: 0 to 4 days). In $72.6 \%$ of cases the injured arrived at the CHU within 24 hours of the trauma. In $19.1 \%$ of the cases the injured had arrived 48 hours after the trauma.

The vulnerable agent responsible for the injuries was a firearm (76.2\%) or a knife $(23.8 \%)$.

On arrival the physical constants of the injured (blood pressure, heart and respiratory rates, temperature) were within the limits of normal. However, $2.4 \%$ of the injured had impaired consciousness and $29.7 \%$ had pallor of the conjunctivae.

Abdominal wounds were mainly in the right hypochondrium (35.7\%), the left iliac fright (17.8\%), and the hypogastrium $(17.8 \%)$. The other regions affected were the left flanks $(8.3 \%)$, right flanks (7.1\%), the left hypochondrium (7.1\%), the epigastrium (4.7\%), and the mesogastre $(1.2 \%)$.

The wounds were punctiform in $81 \%$, linear in $9 \%$ of cases and dilapidated in $10 \%$ of cases.

In the majority of cases the diagnosis of penetration was based on the presence of a hemoperitoneum (57.1\%), followed by signs of peritonitis $(27.4 \%)$. All the signs are reported in the following table.

\begin{tabular}{|c|c|c|}
\hline Signes & Number & $\mathbf{\%}$ \\
\hline Hemoperitoneum & 48 & 57,1 \\
\hline Peritoneal syndrome & 23 & 27,4 \\
\hline Evisceration & 07 & 8,4 \\
\hline $\begin{array}{c}\text { Peritoneal fluid Flow through penetration } \\
\text { orifice }\end{array}$ & 03 & 3,5 \\
\hline finger and the stylet exploration & 02 & 2,4 \\
\hline Projectile inlet and outlet & 01 & 1,2 \\
\hline Total & 84 & 100 \\
\hline
\end{tabular}

Table 1: Distribution of penetrating wounds of the abdomen according to the signs and gestures that made it possible to affirm the diagnosis.
Abdominal wounds were isolated from 61 patients or $72.6 \%$. They were associated with extra abdominal lesions in 15 injured or $17.8 \%$. These are open fractures of the limbs in 10 cases, lesions of the bursa in 3 cases and chest sores in 2 cases.

Therapeutic procedures

Patients received the following resuscitation measures:

- Administration of crystalloid solutes and macromolecules with an average volume of $2000 \mathrm{ml}$ (extremes $500 \mathrm{ml}$ and $3000 \mathrm{ml}$;

- Blood transfusions: 55 injured (65.5\%) were transfused. The average number of units of whole blood transfused was 1.3 (ranges 1 to 4). Most patients (76.4\%) had received a total of two blood bags.

\section{Drug administration}

These are analgesics, no steroidal anti-inflammatory drugs, and tetanic prophylaxis. All patients received antibiotic therapy, including 57 patients $(67.8 \%)$ in triple combination (third-generation cephalosporin, imidazole derivatives and gentamycin) and the other $27(32.2 \%)$ a double combination (betaactamine and gentamycin). The types of antibiotics used are detailed in the table below.

\section{Surgical treatment}

All the injured were operated under general anesthesia with orotracheal intubation. The first route was the median laparotomy above and under umbilical. The organs affected were mainly the liver $(37.1 \%)$, the small intestine $(29.8 \%)$ and the colon $(12.7 \%)$. Details of lesions are reported in table 2.

\begin{tabular}{|c|c|c|}
\hline Visceral Lesions site & Actual & Percentage \\
\hline Liver & 31 & $37,1 \%$ \\
\hline Small bowell & 25 & $29,8 \%$ \\
\hline Colon & 11 & $12,7 \%$ \\
\hline Mesentery & 6 & $07,8 \%$ \\
\hline duodenum & 2 & $02,2 \%$ \\
\hline diaphragm & 4 & $04,6 \%$ \\
\hline No injuries & 5 & $05,8 \%$ \\
\hline Total & 84 & $100,0 \%$ \\
\hline
\end{tabular}

Table 2: Visceral lesions found in injured persons with penetrating wounds of the abdomen. 
Penetrating Wounds of the Abdomen: Treatment in Times of Conflict at the Bangassou Regional University Hospital in the Central African Republic

The surgical procedures performed are presented in table 3.

\begin{tabular}{|c|c|c|c|c|c|c|}
\hline \multicolumn{7}{|c|}{ Method of treatment } \\
\hline Lesions & Number & Simple suture & Tamponade & $\begin{array}{c}\text { partial liver } \\
\text { resection }\end{array}$ & $\begin{array}{c}\text { Resection- } \\
\text { anastomosis }\end{array}$ \\
\hline Resection stoma \\
and stomer & 31 & 24 & 07 & 01 & 00 & 00 \\
\hline Small bowell & 25 & 15 & 00 & 00 & 00 & 00 \\
\hline Colon & 11 & 05 & 00 & 00 & 00 & 00 \\
\hline Mésentère & 06 & 06 & 00 & 00 & 00 & 00 \\
\hline Duodenum & 02 & 02 & 00 & 00 & 00 & 00 \\
\hline Diaphragm & 04 & 04 & 00 & 00 & 00 \\
\hline Total & 84 & 56 & 07 & 01 & 00 \\
\hline
\end{tabular}

Table 3: Surgical procedures according to the visceral lesions found.

\section{Evolution}

We recorded 8 cases of death, or 9.5\%. Five (05) injured had died in the immediate postoperative period, two on Day 2 postoperative and one on Day 3 postoperative all in a hypovolemic shock table. Deaths cases were observed because of the visceral lesions below, mesenteric vessels (4), liver fracture(1), multiple wound of the small intestine (2), wound of the colon and stomach (1).

\section{Discussion}

\section{Epidemiological aspects}

This study made it possible to assess the epidemiological profile, clinical and therapeutic data in injured people with a penetrating wound of the abdomen with a hospital frequency of $8.5 \%$. In the literature, the frequency of penetrating wounds of the abdomen varies from one country to another. In Africa, this frequency was $0.7 \%$ in the Ayite study [1] in Togo, 5.7\% in the Diabetes study in Mali [21]. Doui Doumgba and col had reported, in a study carried out at the CHU de l'Amitié in Bangui, a higher frequency of abdominal wounds or $75 \%$ of cases [22]. In the USA the frequency of penetrating wounds of the abdomen so high as to constitute a public health problem [4]. According to studies, intercommunal conflicts and wars that go hand in hand with the use of firearms and urban violence are at the origin of the resurgence of wounds of the abdomen $[1,21]$.

In most studies, the injured with a penetrating wound of the abdomen are young adults [23-26]. What we found in our study. Indeed, young adults are exposed to the various vagaries of life, in- cluding brawls, drug use, and enlistment in armed groups. In our context, in 2013, a military-political conflict first began in Bangui, and then spread throughout the country including the city of Bangassou, capital of the Mbomou Prefecture, which was one of the epicenters of the conflict with the corollary of the resurgence of wounded abdomens. In our study, most of the injured were male. This predominance of men is also reported in several studies [2325]. In addition, we noted that there were two categories of wounded, indirect victims made up of people who did not take part in the fighting, namely farmers (27 per cent), students (11.9 per cent) and civil servants (1.2 per cent), followed by the other wounded who were involved in the conflict, represented by the unemployed (45.2 per cent). Thus, it is recognized that in a situation of war, penetrating wounds of the abdomen are recurrent. This circumstance alone accounted for $94.8 \%$ of cases in the Bangassou region as well as in Morocco [6] and the Republic of Côte d'Ivoire [27].

\section{Clinicals aspects}

Most of the wounded were treated at the Bangassou University Hospital within a short period of time after the trauma. This is thanks to the help of international non-governmental organizations (NGOs) such as Doctor's without border, the International Committee of the Red Cross, which during the period of the conflict carried out humanitarian activities in the locality. This presence of NGOs often facilitated the transfer of the wounded to the Bangassou University Hospital since for security reasons, only NGOs could circulate with their vehicles. 
For vulnerating agents, most studies have often reported stabbing in varying proportions $[1,4,6]$. On the other hand, in our study firearm projectiles were the main vulnerable agents $(76.2 \%)$ followed by knives $(23.8 \%)$ which come in second place. This is explained by the situation of the military-political conflict that took place in the locality with all its collateral effects.

With regard to the signs observed in the injured, the initial clinical examination of the injured person is a crucial step. It makes it possible to carry out an initial lesion assessment, to eliminate a vital emergency that requires resuscitation measures and sometimes an emergency gesture. The examination of the wounded made it possible to identify the entrance door of the vulnerable agents who sat mainly at the level of the right hypochondrium (35.71\%), the left iliac fright (17.86\%) and the hypogastrium $(17.86 \%)$. The flanks were the seat of the entrance doors in $15.4 \%$ of cases. Indeed, the identification of the seat of the front door of the vulnerating agent is an important step in the clinical examination. It makes it possible to predict the underlying lesion diagnosis. In addition, the penetrating character of the abdominal wound must be proved. For our study, the penetrating nature of the abdominal wound was evoked in front of two main syndromes, including hemoperitoneum and signs of peritonitis. Other signs such as evisceration, the outcome of peritoneal fluid through the wound, the presence of an outlet orifice were observed in varying proportions. For some authors, the signs of penetration were represented by evisceration $[21,26,30]$. But we can also find some non-specific signs such as abdominal defense, abdominal distention, generalized dullness. In these cases, additional examinations are essential. Nowadays, echo tomography and computed tomography have changed the way people are treated in the abdomen [3]. Without being able to detect all the lesions, these examinations make it possible to measure the importance of the trauma and to adapt the most rational therapeutic approach. Computed tomography, in addition to its performance for the diagnosis of hemoperitoneum, is more accurate than ultrasound for the diagnosis of solid organ lesions. In our context none of these morphological examinations has been carried out because it is not available at the Bangassou University Hospital. It was only certain essential biological examinations such as blood type and rhesus, and hematocrit that were performed. They are a reference element for pre- and post-operative resuscitation [10] particularly with regard to blood transfusion.
Therapeutics aspects

The management of trauma to the abdomen in general and wounds to the abdomen in particular has evolved significantly in recent years. In view of the high number of white laparotomy, the debate is between a classic attitude, systematic laparotomy and an attitude called "selective abstentions" or armed expectation advocated especially by Anglo-Saxon authors [3,6]. In the presence of penetrating abdominal trauma, the universally accepted clinical indications for exploratory laparotomy are hemodynamic instability without other identifiable causes, the presence of intestinal or omentum evisceration as well as the presence of diffuse peritonitis, digestive hemorrhage, pneumoperitoneum visible on chest $\mathrm{X}$-ray and a penetrating object still in place [1-4]. In our context, exploratory laparotomy was systematic. This attitude was justified by the nature of the vulnerable agent, which in most cases was a firearm projectile. Thus, visceral lesions were found in $94.2 \%$ of cases. On the other hand, no lesion was found in $5.8 \%$ of the cases operated. In the series observed by Issa-Mapouka and Col [31] on 46 stab wounds of the abdomen the rate of white laparotomy was $47.8 \%$. This rate was $18.5 \%$ over a series of 123 patients operated on for an abdominal wound by Doui Doumgba A., et al. [22]. Indeed, systematic laparotomy in the presence of a penetrating wound of the abdomen frequently does not reveal visceral lesions and is responsible for significant morbidity and mortality. This is the reason why, when the patient has an unstable hemodynamic state, surgical intervention must be done in extreme urgency in order to stop the hemorrhage. Depending on the hemodynamic state and its management by the resuscitators, visceral repairs will be carried out according to the rules of "Damage control" [32,33]. On the other hand, when the patient has a stable hemodynamic state, the dogma of performing a systematic laparotomy in front of any abdominal wound is no longer accepted. Therefore, the penetrating or non-penetrating nature of the abdominal wound must be specified $[32,33]$. In a context where the blunt agent is a firearm. We believe that systematic laparotomy is advantageous insofar as health facilities do not have enough qualified human resources, diagnostic means and resuscitation to ensure good monitoring, carry out sensitive examinations in order to get as close as possible to the lesion diagnosis before deciding on surgery. This attitude reported by several authors in black Africa who urgently have few diagnostic and surveillance means $[27,34,35]$. The visceral lesions found in our study were comparable to those reported by other authors. 
However, liver lesions were in the lead followed by hail and colon lesions unlike other studies where hail lesions rank first [4,36,37].

In our study, treatments for intra-abdominal lesions were similar to those advocated by Masso Misse., et al. in Cameroon [38], Charles and Juglar in France [39] and many other authors [4-6].

\section{Evolution and prognosis}

The evolution of an injured person with an abdominal wound depends on several factors, in particular, the time of therapeutic management, especially in case of hollow organ lesions, associated lesions and finally complications that can enamel the clinical course. For our study, the evolution has been favorable in most cases. The average length of hospital stay for patients was reasonable (09 days). It is comparable to those reported by Diabaté A. [21] in Mali (8.3 days), Moneuse 0., et al. [4] in France (7.5 days) and Mahajna A., et al. [24] in Israel (7.6 days). The mortality rate which was $9.5 \%$ in our study is also close to those reported by Sarré B., et al. [30]. With $10 \%$. Morbidity in our study was characterized by surgical site infection with a proportion of $1.2 \%$. Other authors $[4,24,27]$ reported higher rates ranging from $13 \%$ to $20 \%$. The low rate of infection of the surgical site in our study is justified by the availability of an operating room equipped by MSF, the availability of staff dedicated to the care of the wounded. In addition, the care of the wounded was completely free with the support of Doctors without borders of Belgium at the CHUR of Bangassou.

\section{Conclusion}

The frequency of penetrating wounds of the abdomen is relatively high in our country due to the increase in attacks by firearms or knives favored by military-political conflicts. The victims are mostly young, idle male subjects. Given the context, the lack of qualified human resources and the means of monitoring the wounded, our attitude remains interventionist. However, in view of the lesions observed, some abdominal wounds by firearms can be treated non-operatively in stable patients, without peritoneal signs, highly selected to reduce the number of white laparotomy.

\section{Conflict of Interest}

The authors declare that they have no conflict of interest in relation to this work.

\section{Bibliography}

1. Ayite A., et al. "Les plaies pénétrantes de l'abdomen au CHU de Lomé. A propos de 44 cas". Médecine d'Afrique Noire 43.12 (1996): 642-646.

2. Sarre B., et al. "Les plaies pénétrantes de l'abdomen en pratique de guerre, expérience de BISSAU à propos de 20 cas". Revue Internationale Des Services De Santé Des Forces Armées 73.4 (2002): 229-234.

3. Dieng M., et al. "Plaies pénétrantes de l’abdomen: "abstentionnisme sélectif" versus laparotomie systématique". e-mémoires de l'Académie Nationale de Chirurgie 2.2 (2003): 2225.

4. Monneuse 0., et al. "Les plaies pénétrantes de l'abdomen, conduite diagnostique et thérapeutique, à propos de 79 patients". Annales de Chirurgie 129.3 (2004): 156-163.

5. Naveed A., et al. "The contributions of laparoscopy in evaluation of penetrating abdominal wounds". Journal of the American College of Surgeons 201.2 (2005): 213-216.

6. Nejjar M., et al. "Plaies pénétrantes de l'abdomen à propos de 330 cas". Journal de chirurgie 128 (1991): 381-384.

7. Gaudeuille A., et al. "Les traumatismes abdominaux à Bangui (Centrafrique). Aspects épidémiologiques et anatomocliniques". Mali Médical 22.2 (2007): 19-22.

8. Doui Doumgba A., et al. "Plaie abdominale pénétrante par un corps étranger". Revue Africaine de Chirurgie et Spécialités 2.4 (2008): 39-41.

9. Dufour M. "Anatomie des organes et viscères. Tête, cou et tronc". Elsevier Masson (2013): 248.

10. Pailler JL. “Traumatismes de l'abdomen”. In Boccon GL.

11. Fagniez PL., et al. "Chirurgie digestive et thoracique. Pathologie chirurgicale". Masson 2 (1991): 48-54

12. Philippe B and Daniel J. "Plaie, contusion de l'abdomen”. La Revue du Praticien, Paris 45 (1995): 2205-2213.

13. Lucas CE. "Diagnostic and treatment of pancreatic and duodenal injuries". Surgical Clinics of North America 57 (1997): 4965. 
14. Alve A., et al. "Stratégie diagnostique face aux plaies de l'abdomen". Annales de Chirurgie 52.9 (1998): 927-934.

15. Evatuy RR., et al. "A critical evaluation of laparoscopy in Penetrating abdominal trauma". Journal of Trauma 34 (1993): 822-828.

16. Schren P., et al. "Diagnostic laparoscopy: a survey of 92 patients". American Journal of Surgery 30 (1990): 82-88.

17. Dumurgier C L., et al. "Plaies de l'abdomen par projectile de guerre (Expérience du détachement médical de Kousseri Kiggil 15/07/80 au 15/12/99". Médecine et hygiène 40 (1982): 2974-2982.

18. Saegesser FL. "Plaie de l'abdomen". Médecine et Hygiène 40 (1982): 2972-298.

19. Burch J M. "New concepts in trauma”. American Journal of Surgery 118 (1997): 736-771.

20. EL Idrissi H D., et al. "Les plaies pénétrantes de l'abdomen. Résultats des deux attitudes classiques et sélectives dans la prise en charge de 249 plaies". Journal de Chirurgie 131.8-9 (1994): 375-377.

21. Moore EE., et al. "Mandatory laparotomy for gunshot wound penetrating the abdomen". The American Journal of Surgery 140 (1980): 847-851.

22. Diabate A. "traumatisme ouvert de l'abdomen dans le service de chirurgie générale et pédiatrique du chu gabriel toure". Thèse méd. Bamako (2002): 32.

23. Doui Doumgba A., et al. "Traitement et évolution des traumatismes abdominaux à Bangui (Centrafrique)". Revue Africaine de Chirurgie 9.1 (2006): 9-12.

24. Bergeron E Andre L., et al. "Penetrating thoraco-abdominal injury in Quebec: implications for surgical training and maintenance of competence". Canadian Journal of Surgery 48.4 (2005): 284-287.

25. Mahajna A., et al. "Diagnostic laparoscopy for penetrating injury in the thoraco abdominal region". Surgical Endoscopy 26 (2004): 1-6.
26. Fall B., et al. "Evaluation du traitement conservateur des plaies pénétrantes de l'abdomen par arme à propos de 40 cas". $D a$ kar Medical 47.1 (2002): 6-9.

27. Soykan A., et al. "A prospective comparison of the selective observation and Routine exploration methods for penetrating abdominal stab wounds with organ or omentum evisceration". Journal of Trauma 58.3 (2005): 526-532.

28. Koffi E., et al. "Les traumatismes de l'abdomen". Medical Chirurgie Digest 25 (1996): 79-95.

29. Robert A., et al. "The role of laparoscopy in penetrating abdominal stab wounds". Surgical Laparoscopy Endoscopy and Percutaneous Techniques 15.1 (2005): 14-17.

30. Keita $S$. "Problème diagnostique et thérapeutique des abdomens aigus en chirurgie. A propos de 182 cas à l'hôpital national du point". Thèse méd. Bamako (1996): M13.

31. Sarre B., et al. "Les plaies pénétrantes de l'abdomen en pratique de guerre, expérience de BISSAU à propos des 20 cas". Revue Internationale Des Services De Santé Des Forces Armées 73 (2002): 229-234.

32. ISSA MAPOUKA PA., et al. "Les plaies pénétrantes de l'abdomen par arme blanche à l'Hôpital Communautaire de Bangui : prise en charge et résultats". Annales Université de Bangui Série D 2.2 (2016): 39-42.

33. Haddad K. "Contusions et Plaies de l'abdomen. Accessible sur Error! Hyperlink reference not valid". Consulté le (2019).

34. Zingg T., et al. "Recommandations de Pratiques Cliniques Traumatisme abdominal pénétrant”. Filière Trauma (2014): 7.

35. Gaudeille A., et al. "Profil des urgences chirurgicales en zone rurale : exemple de l'hôpital régional de Bambari en Centrafrique". Dakar Medical 47 (2002): 983-987.

36. Bbikandou G., et al. "Les plaies de l'abdomen en pratique civile: à propos de 80 cas". Médecine d'Afrique Noire 42 (1995): 75-79.

37. Angate Y A and Cornet I. "Les traumatismes ouverts de l'abdomen en milieu ivoirien. Etude rétrospective d'une série de 652 cas". Chirurgie 113 (1987): 451-459. 
38. Masso-Misse P., et al. "Plaies pénétrantes de l’abdomen et laparotomies inutiles". Médecine et Chirurgie Digestives 23 (1994): 283-284.

39. Masso-Misse P., et al. "Hémopéritoine et contusions de l'abdomen. Apport de l'échographie dans la stratégie décisionnelle en situation hémodynamique stable". Médecine d'Afrique Noire 42 (1996): 102-104.

40. Charles JF and Juglar G. "Traumatismes fermés de l'abdomen: physiopathologie, diagnostic et traitement". Review Practice 47 (1992): 983-987.

\section{Assets from publication with us}

- Prompt Acknowledgement after receiving the article

- Thorough Double blinded peer review

- Rapid Publication

- Issue of Publication Certificate

- High visibility of your Published work

Website: www.actascientific.com/

Submit Article: www.actascientific.com/submission.php

Email us: editor@actascientific.com

Contact us: +919182824667 